\title{
Summary Report on the Transportation Combustion Engine Efficiency Colloquium Held at USCAR, March 3 and 4, 2010
}

\section{Executive Summary}

This report summarizes results from an invited two-day colloquium of twenty-nine combustion engine experts from academia, industry, and national labs that was convened March $3^{\text {rd }}$ and $4^{\text {th }}, 2010$, at the headquarters of the United States Council for Automotive Research (USCAR) in Southfield, Michigan. The colloquium was held at the request of The Department of Energy (DOE) Office of Freedom Car and Vehicle Technologies (OFCVT) to review and assess the current state of transportation combustion engine technology from theoretical and practical perspectives. In the ensuing discussions, the experts were able to reach a broad consensus on some important questions regarding current fuel efficiency limits. They also identified technology barriers and recommended specific near and longer-term R\&D priorities for DOE's consideration.

\section{Key Technical Questions}

The colloquium agenda was structured around presentations by eleven of the participants, breakout group discussions, and general discussions among the entire group. Major points raised during these discussions are summarized below:

\section{Ideal Efficiency Limits}

- The highest peak brake thermal efficiency (BTE) of current passenger vehicle engines is slightly above $40 \%$, meaning that more than $40 \%$ of the energy released by the fuel is converted into crankshaft work under ideal conditions.

- The maximum BTE expected for slider-crank engines is about $60 \%$, assuming that cost is not a constraint.

- Existing engines lose 20-25\% of the fuel exergy due to the irreversibility of unrestrained (non-equilibrium) combustion. The destroyed exergy appears as heat that cannot be transformed into useful work.

- Achieving BTEs >60\% will require radical changes to present engines including: cycle compounding; new engine architectures; and more constrained combustion reactions. Such radical changes require long-term $R \& D$ to bear fruit, but work in this direction needs to begin now.

- Estimates for the maximum achievable peak BTE for modified architecture engines range considerably, but generally they were all $<85 \%$.

- An important challenge in future engine development will be to maintain or increase specific power with increasing efficiency.

- Additional peak efficiency gains are still possible for slider-crank engines. Some gains are likely to come from lower combustion temperatures through various forms of lean, premixed or partially premixed combustion. Lower combustion temperatures are also useful for reducing engine out nitrogen oxide (NOx) emissions, thereby reducing fuel penalties for exhaust aftertreatment. 
- Cost, consumer driving needs and comfort, and environmental regulations can often play a greater role than direct fuel consumption in the marketplace. The practical limit for the peak BTE of slider-crank engines is significantly $<60 \%$ when these additional factors (particularly cost) are considered.

- The central efficiency objective should be higher cycle-average vehicle fuel efficiency, not just higher peak engine efficiency. Focusing on peak efficiency alone can potentially lead to non-optimal cycle-average efficiency.

- Appropriate targets for drive cycle efficiency depend heavily on which transportation sector is considered (e.g., light duty (LD), hybrid, or heavy duty (HD)). HD BTEs generally may be as much as $10 \%$ higher compared to LD.

- Improving overall vehicle system integration is probably the single most effective route to large, near-term fuel efficiency increases (up to a factor of 2 for LD drive cycle averages). Many current engines operate far below peak efficiency.

- New technologies such as variable expansion/compression cycles and hybridization can help achieve engine downsizing and downspeeding, which will allow significant efficiency gains without major changes to engine architecture.

- Vehicle integration requires a hierarchy of simulation tools ranging from fundamental combustion to aftertreatment to full vehicle simulation.

- Hybridization offers significant potential for decoupling engine operation and instantaneous power demand.

- A goal of 50\% average drive cycle energy efficiency (tank to wheels) would be reasonable for a fully optimized vehicle.

\section{Advanced Combustion Modes and Alternative Fuels}

- An important challenge in widely implementing LTC is to stabilize and control it at high loads where engine efficiencies are high.

- High EGR and lean combustion have increased irreversibility losses, but higher single-stage efficiencies are possible due to reduced cylinder-wall heat losses and improved thermodynamic properties of the expanding exhaust gases.

- High EGR and lean combustion require boosting, but more efficient engines have less exhaust energy for boosting. Current turbochargers have limited efficiency.

- Dual fueling has been demonstrated to reduce combustion stability and combustion phasing problems associated with LTC and high EGR operation.

- Lifted flame diesel combustion appears to offer some of the benefits of LTC using conventional combustion and a modified fuel injection system.

- Oxygenated fuels have efficiency and emissions benefits, but their distinct properties and uncertain availability will require adaptive on-board sensors and controls to fully exploit their potential.

\section{Advanced Engine Materials and Friction Reduction}

- Improved engine materials can benefit in multiple ways, including reduced heat losses, decreased cooling cost, and increased peak cylinder pressure. However, such materials must be affordable and efficiently integrated with engine design.

- Higher cylinder pressure improves the potential for generating expansion work. With current engines, friction losses begin to overwhelm efficiency gains at 
compression ratios higher than about 20. The structural integrity of cost effective cylinder and piston materials also becomes limiting.

- Reduced friction is of high value because it translates directly into power out. Expected friction reduction benefits range from 1 to $7 \%$ increase in BTE.

- Material thermal properties are important not only for reducing heat losses but because of the energy expended to maintain engine components below their critical temperature limits. Potential efficiency benefits associated with reduced heat loss and cooling loads could amount to $3 \%$.

\section{Advanced Engine Architectures}

- Fully expanded engine cycles are able to extract additional work from the exhaust gas that is usually wasted. Variable valve actuation can allow exploitation of fully expanded cycles, potentially improving peak engine efficiency a few percent.

- Advanced engine architectures will likely include modifications to the combustion chamber geometry and utilization of cycle compounding.

- It may be possible to exploit some of the physics behind large marine engines with novel engine geometries to achieve more efficient compact engine designs.

- One geometric factor deserving further study is the ratio of the combustion chamber surface area to the surface area of a sphere of equivalent volume. This ratio captures effects of combustion chamber wall heat transfer rate and time in a way that might be generally applied to other combustion chamber geometries.

- A proposed new engine design that exploits geometric factors not accessible to slider-crank engines is the compact compression ignition (CCI) engine.

- Free piston engines appear to achieve low friction, high compression ratio, LTC compatibility, and reduced wall heat transfer losses compared to conventional engines. Reported BTEs for experimental free piston engines approach $60 \%$.

- Cycle compounding has the theoretical potential to increase BTE by $10 \%$ or more. This is evidenced by existing compound cycle turbines (gas/steam cycles) and turbine-fuel cell combinations, which have demonstrated BTEs of over $60 \%$.

- Addition of bottoming cycles is one possible approach for cycle compounding, but this is inherently limited by engine-out exhaust enthalpy, which continues to decrease as the first-stage engine efficiency is pushed progressively higher.

- In the longer term, it is likely that the most efficient cycle compounding will either include radical changes to slider-crank architecture or utilization of topping and parallel cycles such as combustion engine-fuel cell combinations.

\section{Major Technology Barriers}

In the breakout group discussions, the following technology barriers were identified as the most important limits on development of more fuel efficient engines and vehicles:

\section{$\underline{\text { Fuels }}$}

- High lean flammability limits;

- High fuel variability and inadequate fuel standards; and 
- Impact of fuel variability on advanced combustion modes.

\section{$\underline{\text { Emissions }}$}

- Fuel penalty for lean NOx aftertreatment; and

- High cold start emissions.

\section{$\underline{\text { Analysis and Simulation }}$}

- Inadequate computational and analytical tools to span from detailed combustion modeling to integrated systems simulations; and

- Inadequate experimental platforms for validating models and simulations.

\section{Materials and Equipment}

- Ineffective, limited operating range fuel injectors;

- Low engine material temperature and strength limits;

- Inefficient turbo-machinery;

- High materials and packaging costs;

- Packaging and power density; and

- High cylinder wall heat losses.

\section{Instrumentation and Controls}

- Inadequate, low-cost on-board sensors for combustion, fuel diagnostics, and controls;

- High noise, vibration, and harshness (NVH) of advanced combustion modes; and

- Shifts in engine power demand during drive cycles.

The breakout groups also recommended $R \& D$ areas deserving the most attention in the near term $(<10$ years) and longer term $(>10$ years). These are summarized below:

\section{Near Term Priorities ( $<10$ years)}

- Integrated engine/vehicle system optimization;

- Expanded LTC envelope and combustion mode control;

- Greater understanding and utilization of fuel chemistry;

- Improved engine materials and reduced friction;

- Waste heat recovery and cycle compounding; and

- Advanced engine architectures.

\section{Longer Term Priorities ( $>10$ years)}

- Continued integrated engine/vehicle system optimization;

- Further advancement in fuel chemistry utilization;

- Advanced engine architectures (beyond slider crank);

- Continued improvement of engine materials and friction reduction;

- Expanded HECC envelope and combustion mode control; and 
- Waste heat recovery and cycle compounding

\section{Introduction}

Internal combustion engines currently play a dominant role in U.S. transportation and are expected to continue to do so well beyond 2020 [1]. Because of this, the Department of Energy (DOE) has placed high priority on promoting technologies that maximize combustion engine fuel efficiency while minimizing greenhouse gas emissions. Identification of the most promising paths to achieve these goals has recently become more complicated as non-traditional transportation fuels and hybrid electric vehicles become widely available. To reassess the state of combustion engine science and identify new opportunities for technology breakthroughs, an invited colloquium of combustion engine experts was convened on March $3^{\text {rd }}$ and $4^{\text {th }}, 2010$, at the headquarters of the United States Council for Automotive Research (USCAR) in Southfield, Michigan.

The colloquium objectives were:

- Review and assess the current state of transportation combustion engine technology from both theoretical and practical perspectives;

- Arrive at a consensus on the theoretical and practical fuel efficiencies that can be achieved;

- Recommend near and longer-term R\&D priorities for DOE to consider in developing their strategic planning for reaching efficiency goals.

This report summarizes the main discussion points and recommendations that emerged from the meeting. Included are areas where there is widespread consensus and areas where there are still important technical uncertainties and wide ranging opinions.

\section{Participants and Meeting Agenda}

Twenty-nine participants were invited from industry, academia, and government based on their combustion engine experience and recognized technical expertise. A complete list of the participants with their affiliations and the meeting agenda are given in the Appendix. On the first day, eleven volunteers from among the participants gave short overview presentations in their respective areas of expertise, followed by interactive discussions with the entire group. Electronic copies of these presentations are available on the internet at (XXXXX-to be added later).

On the second day, each of the participants was assigned to one of five breakout groups, which then separately discussed a predefined list of questions/issues during two separate breakout periods. Following the breakout discussions, all of the groups recombined to hear and discuss summary reports from each group. The meeting highlights summarized below have been derived from the individual and group presentations and discussions 
from both days. The topic areas for the individual presentations on the first day and the questions for the group discussions on the second day are summarized in the appendix.

\section{General Comments and Observations}

\section{Ideal Efficiency Limits}

The theoretical peak energy efficiency limits for combustion engines are constrained by the $1^{\text {st }}$ and $2^{\text {nd }}$ Laws of thermodynamics as they apply to the chemical and physical processes involved in converting fuel chemical energy into force and motion. There are well-understood reasons why these theoretical limits can never be reached in practice, but it is still important to understand what the theoretical limits are in order to set realistic upper performance bounds and identify which $R \& D$ paths might be the most productive to pursue.

The ultimate measure of engine efficiency is how much of the original chemical energy originally available in the fuel is converted to mechanical work. Fuel energy is typically quantified in terms of both heating value and exergy, which respectfully describe the amount of energy released when the fuel is burned and the degree to which that energy can be converted into mechanical work. Currently, the highest peak brake thermal efficiency (BTE) of passenger vehicle engines is slightly above $40 \%$, meaning that somewhat more than $40 \%$ of the energy released by burning the fuel is converted into work by the crankshaft under ideal operating conditions. Most of the colloquium participants agreed that the maximum BTE that could be achieved with slider-crank architecture (the dominant mechanical architecture of current engines) is about $60 \%$, assuming that cost is not a constraint.

One major reason why BTEs above $60 \%$ are not possible is the inherent irreversibility of unrestrained combustion. As illustrated by the first and second law analyses for an engine in Figure 1, 20-25\% of the fuel exergy is destroyed by the unrestrained combustion of hydrocarbon fuels (i.e., when the combustion reactions occur far from thermodynamic equilibrium). Although none of the combustion heat is destroyed (guaranteed by the 1st Law), the 2nd Law of thermodynamics prevents a significant portion of the heat (20$25 \%$ ) from being transformed into useful work. This large loss of useful energy due to combustion irreversibility is an inherent feature of all current combustion engines. Figure 2 provides another illustration of the impact of chemical reaction irreversibility, this time including a comparison of an engine with a solid oxide fuel cell (SOFC). Because the chemical reactions proceed very differently in the SOFC, they can be constrained in ways not possible for the combustion engine. However, uncontrolled irreversibilites in the SOFC associated with transport processes still take a significant toll on efficiency.

Achieving BTEs higher than $60 \%$ will require radical changes to present engines including: cycle compounding (which might include fuel cells); non-slider-crank engine architectures; and more constrained combustion reactions (reactions closer to equilibrium). Such radical changes will require long-term R\&D effort to bear fruit, but there is general agreement that the time to start working on them is now. Opinions at the colloquium were wide-ranging about the maximum achievable peak BTE for modified 
architecture engines with reduced combustion irreversibility, but generally they were all below $85 \%$. Another important constraint to recognize is that past work has indicated higher engine efficiency appears to correlate with lower power density. Thus a challenge for future development will be to obtain higher efficiencies while still maintaining or increasing specific power.

In the nearer term, it appears that additional gains in peak efficiency are still possible for slider-crank combustion engines. Many of these gains are likely to come from reduced heat losses achieved by lowering combustion temperatures through various forms of lean, premixed or partially premixed combustion. Recent examples of the efficiency impact of these new low-temperature combustion (LTC) modes are illustrated in Figures 3-5. The lower reaction temperatures in LTC are also useful for reducing engine out nitrogen oxide (NOx) emissions, thereby reducing the need to consume additional fuel for exhaust aftertreatment. Thus, at least for NOx, low-emission combustion does not necessarily have a negative impact on efficiency.

\section{Practical Efficiency Limits}

Commercially achievable engine efficiencies are constrained not only by the basic chemistry and physics but also by important economic, social, and engineering concerns. In particular, factors such as cost, consumer driving needs and comfort, and environmental regulations can often play a greater role than fuel consumption in the real world marketplace. With this in mind, there was considerable discussion in the colloquium about what realistic engine efficiency targets should be.

There was a general consensus that the practical limit for peak BTE for slider-crank engines is significantly less than $60 \%$ when these additional factors (particularly cost) are considered. It was also repeatedly emphasized that the central objective should be to increase cycle-average vehicle fuel efficiency, not just peak engine efficiency. The consideration of driving cycles also implies that practical fuel efficiencies will depend heavily on which transportation sector is targeted (e.g., light duty (LD), hybrid, or heavy duty (HD)). Many commented that HD BTEs should generally be as much as $10 \%$ higher compared to LD.

A recurring theme in the discussion was that improving integration among engine, aftertreatment, and other vehicle systems is probably the single most effective route to large, near-term fuel efficiency increases (up to a factor of 2 for light duty drive cycle averages). Many current engines are not well-matched to their drive cycle speed and load demands, so that on average they operate far below their peak efficiency. This is graphically illustrated in Figure 6, which compares the speed and load range where a typical passenger car engine actually spends most of its time operating with the speed and load range where the engine approaches its peak efficiency. By downsizing and downspeeding engines with the help of new technologies such as variable expansion/compression cycles and hybridization, significant efficiency gains can be accomplished without major changes to engine architecture. 
Global integrated system efficiency optimization will require a hierarchy of simulation tools of varying computational complexity and detail ranging from fundamental combustion chemistry to full vehicle simulation. In addition to engine models capable of simulating the efficiency and emissions effects of drive cycle transients, it will be important to simulate engine coupling with bottoming cycles and aftertreatment emissions controls to fully account for the relationships that drive overall fuel consumption. The interaction of these factors is especially important when considering hybridization, which offers significant potential for decoupling engine operation and instantaneous power demand.

Besides increasing possibilities for exhaust heat utilization, hybridization is especially attractive because it can recover inertial energy from the vehicle, in effect recuperating mechanical energy previously released by the engine. Clearly the fuel efficiency benefits of inertial energy recovery depend heavily on drive cycle details and need to be assessed in that context. The traditional design constraints of designing engines for high power density and minimum engine-out NOx likewise need to be revisited as well when considering the possibilities offered by hybridization.

Considering the above points, it was suggested that we should consider establishing a goal of achieving 50\% average drive cycle energy efficiency (tank to wheels) with fully optimized engine-vehicle systems (e.g., making use of hybridization and/or other means for staying close to peak engine performance and maximizing utilization of waste heat).

\section{Advanced Combustion Modes and Alternative Fuels}

Various versions of low-temperature combustion (LTC) have been intensely investigated for the past several years because of their potential for generating reduced combustion temperatures and NOx emissions. Lower engine-out NOx is beneficial for diesel and lean gasoline engines because it reduces the fuel required to reduce the NOx with post-engine aftertreatment for emissions control. The benefits from low-temperature combustion also extend directly to engine efficiency, primarily because of reduced cylinder heat losses (due to the lower combustion temperature) and the potential for very dilute combustion (due to different reaction kinetics). By reducing cylinder heat losses and changing the molecular properties of the expanding combustion gases, LTC allows more of the energy released by combustion to be extracted in the expansion stroke as illustrated in Figure 3. This is beneficial even though the combustion reactions are not moved significantly closer to equilibrium and thus the overall combustion thermodynamics are still irreversible. The combustion irreversibility even increases further with dilute combustion due to the added entropy generation from inert gas mixing. Yet in spite of these irreversibility penalties, the reduced heat losses and better gas properties in LTC are enough to improve net work output. Thus it is now understood that it is possible to actually increase combustion irreversibility (at least a modest amount) and still improve overall engine efficiency.

The biggest challenge in widely implementing LTC is that it is less stable and more difficult to control than conventional diesel and spark ignition combustion, especially at high loads where engine efficiencies are high. Some modes of LTC are also apparently 
sensitive to small changes in fuel properties. While some engine LTC experiments have apparently demonstrated peak net indicated efficiencies in excess of 55\%, this has been achieved under idealized laboratory conditions. There were widely varying opinions among the colloquium participants regarding how well these results would translate to actual drive cycle conditions.

A further challenge to highly dilute combustion - whether the dilution occurs through lean operation (i.e., high excess air) or through exhaust gas recirculation (EGR) or both is achieving acceptable power densities with current boosting equipment (e.g., turbochargers). Since dilute operation requires increased mass flow through the engine, the current power density requirements make boosting high EGR engines a necessity. Unfortunately, high efficiency operation leads to lower exhaust enthalpy (less for driving turbochargers), which makes achieving high mass flows and high pressures in the intake manifold much more challenging. Currently available boosting systems are significantly limited in efficiency, particularly in the flow range required for light duty (LD) applications. In addition, the points of highest boost efficiency are restricted to a small portion of the engine operating range. The combination of these factors can lead to severe reductions in the brake efficiency of the engine under realistic driving conditions, particularly when compared to the ideal efficiencies achieved in the laboratory.

Non-traditional oxygenated fuels, such as methanol, ethanol, and dimethyl ether, have been demonstrated to have fuel efficiency and emissions benefits relative to conventional fuels (on an energy input basis). However, the distinctly different properties of such fuels and their variable availability in the present infrastructure will require much improvement in adaptive on-board sensors and controls to be able to fully exploit the potential benefits. The reasons for these benefits from oxygenated fuels are not yet well understood, but many of the assembled experts argued that such fuels used alone or in combination with conventional hydrocarbon fuels (in so-called dual fuel combustion) offer important new opportunities for increased efficiency. One other possible advantage of these fuels is that they can be relatively easily reformed to produce hydrogen and carbon monoxide (syngas). Because the reforming reactions are endothermic, it is possible to use this process to recuperate exhaust heat and increase the effective heating value of the fuel. The different ignition properties of the syngas also make it useful for possible use in dual fueling as described below.

Dual fueling (i.e., feeding two distinctly different fuel types into the engine simultaneously or at different stages of the combustion) appears to offer important advantages in improving the combustion stability problems associated with LTC and high EGR operation. The potential impact of gasoline-diesel dual-fuel combustion on improving the efficiency of various types of LTC are illustrated above in Figures 3-5. Additional examples of the use of gasoline and diesel dual-fueling and gasoline and ethanol dual-fueling are depicted in Figures 7 and 8, respectively. In all of these cases the different ignition properties and combustion kinetics of the two fuels are exploited to modulate the combustion in ways that optimize ignition stability and phasing. 
Apart from LTC and dual fueling, other types of unconventional combustion are available for enhancing engine efficiency. One of the most prominent of these is lifted flame combustion, which utilizes special injection technology to shift the diffusion flame in diesel combustion away from the cylinder walls. An example of the impact this type of combustion can have on efficiency and emissions is illustrated in Figure 9.

\section{Advanced Engine Materials and Friction Reduction}

There was broad agreement among the participants that advanced engine materials can be of benefit in multiple ways, including reduced heat losses, decreased energy expenditures for cooling, and enabling increased peak cylinder pressures. However, practical commercial utilization also requires that such materials are affordable and can be integrated efficiently with engine design.

Higher cylinder pressures are important because they directly affect the thermodynamic potential for generating expansion work. In the limit of extremely high compression ratios (e.g. 100), it is theoretically possible to achieve efficiencies approaching $70 \%$, but with current engines, friction losses begin to overwhelm any gains at compression ratios higher than about 20. As discussed below, overcoming friction losses at such extreme pressures will require very different types of engine architectures (e.g., free pistons). However, even with current engines, reduced friction (from either new materials or improved lubricants) is of very high value because it translates directly into power out.

Reduced heat transfer is often more difficult to utilize than reduced friction because it does not directly result in increased power. There are several areas where mechanical friction reduction can yield efficiency increases, but there were widely differing opinions on the size of the expected benefit. Estimates ranged from 1 to $7 \%$ potential efficiency improvement associated with friction reduction.

Material thermal properties are important not only for reducing heat losses (e.g., by being more insulating) but also because of the energy (fuel) expended to maintain engine components below their critical temperature limits. Some participants suggested that potential efficiency benefits associated with reduced heat loss and cooling loads could amount to $3 \%$.

\section{Advanced Engine Architectures}

Architectural changes to engine design that might lead to increased efficiency were a major topic of the colloquium discussion also. One beneficial change that has already been successfully implemented on slider-crank engines is to allow the exhaust gases to fully expand to atmospheric pressure before they are released. This constitutes the basis of the so-called fully expanded or Atkinson cycle, which is able to extract additional work from the exhaust gas that is usually wasted in conventional engines. Full expansion is not possible in conventional engines because of the physical limitations of camoperated intake and exhaust valves. However, new engine designs with variable valve actuation are now becoming available, and these can potentially provide peak engine efficiency improvements of a few percent. 
As noted above, the slider-crank architecture that dominates current engines has inherent thermodynamic limitations that can (at least in principle) be overcome by major structural changes. The main types of architectural changes discussed in the colloquium included modifications to the basic geometry of the combustion chamber/piston in single-cycle engines and utilization of cycle compounding so that the fuel energy is converted to work in more than one thermodynamic cycle. One important clue regarding potential architectural changes that might be exploited is the surprisingly high efficiencies (e.g., approximately 55\%) achieved by large marine engines. Although these engines are still based on the slider-crank mechanism, they have a very favorable combination of piston geometry, speed, turbocharging, and direct drive (no transmission) which makes them the most efficient reciprocating engines available (Figure 10).

The large dimensions and special requirements of marine engines precludes their utilization for automotive and truck applications, but an analysis of the physics behind their high efficiency helps to identify how some aspects of their improved combustion shape, reduced friction, and low heat loss can be captured with other architectures. For example, these analyses have led to the recognition of the importance of the ratio of the combustion chamber surface area to the surface area of a sphere of equivalent volume. This characteristic ratio captures both the effects of combustion chamber wall heat transfer rate and time in a way that can be applied to many types of combustion chamber geometry. Implementations of this and other principals into a compact form have led to engine concepts with very different mechanical form. One example is the compact compression ignition (CCI) engine design described by John Clarke at the colloquium. Details of this design can be found in [11] and [12].

Another specific alternative architecture mentioned repeatedly in the discussion was the free-piston engine. Briefly, this type of combustion engine utilizes a linear piston motion that is not connected to a crankshaft but instead is coupled to a rebound device (e.g., another opposed combustion chamber) and a load device (e.g., a linear alternator). Potential advantages of the free-piston concept include low friction, high compression ratio (variable to allow optimization with varying speed and load and changes in fuel quality), compatibility with LTC, and reduced wall heat transfer losses. Recently reported BTEs for experimental free piston engines are approaching 60\% (see Figures 11 and 12 for example), but there are still major challenges to be overcome including large cycle-tocycle combustion variations and transient engine control.

Regardless of the engine combustion chamber and piston design, cycle compounding has the theoretical potential to increase BTE by $10 \%$ or more. This is clearly evidenced by existing compound cycle turbines (gas/steam cycles) and turbine-fuel cell combinations, which have demonstrated BTEs of over $60 \%$. Addition of bottoming cycles to existing slider-crank engines (e.g., organic or steam Rankine cycles or thermoelectrics) is one possible approach for cycle compounding. But this approach is inherently limited in potential by engine-out exhaust enthalpies, which continue to decrease as the the firststage engine efficiency is pushed progressively higher. The relative value of bottoming cycles will also be very dependent on vehicle size and drive cycle demands as depicted in Figure 13. 
In the longer term, it is more likely that the most efficient cycle compounding approaches will either include radical changes to the slider-crank architecture or utilization of topping and parallel cycles such as combustion engine-fuel cell combinations. The latter could be particularly appropriate in the case of hybrid vehicles.

\section{Technology Barriers}

In the breakout group discussions, participants were asked to identify major technology barriers currently limiting development of more fuel efficient engines and vehicles. Highlights from the group reports are summarized below.

\section{Fuels}

- High lean flammability limits;

- High fuel variability and inadequate fuel standards; and

- Impact of fuel variability on advanced combustion modes.

The degree to which lean combustion can be exploited is directly dependent on the lean ignition behavior of the available fuel. Fuel ignition variability is increasing as biofuels and other non-conventional fuels become more available and engine fuel standards are heavily challenged to keep up with the changing supply. Since LTC technology is still being developed, it is difficult to anticipate how future fuels might change the needs for on-board LTC diagnostics and controls.

\section{Emissions}

- Fuel penalty for lean NOx aftertreatment; and

- High cold start emissions

Since conventional 3-way catalysts are unsuitable for lean NOx emissions control, alternative aftertreatment catalysts must be used. These catalysts require additional fuel to operate and result in a NOx control fuel penalty. The NOx control fuel penalty typically increases as the combustion is driven leaner because of the drop in exhaust temperature and catalyst activity. During cold start, high engine-out $\mathrm{CO}$ and hydrocarbons pass through the aftreatment system with little conversion until the oxidation catalyst warms sufficiently to become active.

\section{Analysis and Simulation}

- Inadequate computational and analytical tools to span from detailed combustion modeling to integrated systems simulations; and

- Inadequate experimental platforms for validating models and simulations.

Integrated optimization of vehicle efficiencies will require development and use of a hierarchy of computer models and analytical tools to capture the complex interactions among the engine, aftertreatment, and auxiliary powertrain components during realistic 
drive train transients. The multiple physical phenomena that need to be accounted for include thermodynamics, computational fluid dynamics, chemical kinetics, mechanics, and heat transfer. Ultimately, global performance assessment tools are needed to better and more consistently "screen" new concepts. Experimental validation of model predictions at all levels will be critical to success.

\section{Materials and Equipment}

- Ineffective, limited operating range fuel injectors;

- Low engine material temperature and strength limits;

- Inefficient turbo-machinery;

- High materials and packaging costs;

- Packaging and power density; and

- High cylinder wall heat losses.

These involve a range of material components that directly affect engine efficiency as well as factors related to economics and marketability. In some cases improved materials already exist, but their commercial use is constrained by high cost.

\section{Instrumentation and Controls}

- Inadequate, low-cost on-board sensors for combustion and fuel diagnostics and controls;

- High noise, vibration, and harshness (NVH) of advanced combustion modes; and

- $\quad$ Shifts in engine power demand during drive cycles.

Implementation of very lean and LTC combustion conditions poses special control challenges, particularly when rapid combustion transitions (e.g., transitions from sparkignited to LTC combustion) are required by drive cycle transients. In some instances the associated combustion instabilities lead to large amplitude vibrations and noise that can impact customer acceptance. Fuel variability can further exacerbate combustion instabilities through uncontrolled pre-ignition.

\section{Recommended R\&D Priorities}

As part of the breakout group discussions, participants were also asked to recommend which $R \& D$ areas deserved the most attention in the near term ( $<10$ years) and longer term ( $>10$ years). Those areas most frequently cited by the breakout groups for each category are listed below (not necessarily in order of priority).

\section{Near Term Priorities (<10 years)}

- Integrated engine/vehicle system optimization;

- $\quad$ Expanded LTC envelope and combustion mode control; 
- Greater understanding and utilization of fuel chemistry;

- Improved engine materials and reduced friction;

- Waste heat recovery and cycle compounding; and

- Advanced engine architectures.

Most groups noted that practical utilization of results from some of the above R\&D (such as advanced engine architectures) would not likely occur within the near-term time frame, but they emphasized that work needs to be initiated now in order for the technology to be ready for implementation in future engines.

\section{Longer Term Priorities (>10 years)}

- Continued integrated engine/vehicle system optimization;

- Further advancement in fuel chemistry utilization;

- Advanced engine architectures (beyond slider crank);

- Continued improvement of engine materials and friction reduction;

- Expanded HECC envelope and combustion mode control; and

- Waste heat recovery and cycle compounding

Especially for R\&D oriented to the longer-term, many of the assembled experts felt it is important to emphasize new engine concepts and "out of box thinking". Identification of cycle compounding opportunities, new engine architectures beyond the slider-crank, and more reversible modes of combustion (not necessarily internal combustion) were deemed to be especially important for developing engines capable of peak BTEs greater than $60 \%$. 


\section{References}

1. "Real Prospects for Energy Efficiency in the United States," Report by the National Academy of Sciences, Washington, D.C., 2009.

2. C.D. Rakopoulos and E.G. Giakoumis, "Second-law analysis applied to internal combustion engine operation,” Progress in Energy and Combustion Science, vol. 32, pp 2-47 (2006).

3. N. Lior and G.J. Rudy, "Second-law Analysis of an Ideal Otto Cycle, Energy Conversion and Management, vol. 28, no. 4, pp 327-334 (1988).

4. R.J. Primus, K.L. Hoag, P.F. Flynn, and M.C. Brands, “Appraisal of advanced engine concepts using second law analysis techniques," SAE 840032R.

5. L. Staples and R. Reitz, C. Hergart, "An Experimental Investigation into Diesel Engine Size-Scaling Parameters”, SAE 2009-01-1124.

6. W. Hardy and R. Reitz, "A Study of the Effects of High EGR, High Equivalence Ratio, and Mixing Time on Emissions Levels in a Heavy-Duty Diesel Engine for PCCI Combustion”, SAE 2006-01-0026.

7. R. Hanson, D. Splitter, and R. Reitz, “Operating a Heavy-Duty Direct-Injection Compression-Ignition Engine with Gasoline for Low Emissions”, SAE 2009-01-1442.

8. R. Hanson, S. Kokjohn, D. Splitter, and R. Reitz, "An Experimental Investigation of Fuel Reactivity Controlled PCCI Combustion in a Heavy-Duty Engine,” SAE 2010-010864.

9. L. Hildingsson, G. Kalghatgi, N. Tait, B. Johansson, and A. Harrison, "Fuel Octane Effects in the Partially Premixed Combustion Regime in Compression Ignition Engines," SAE 2009-01-2648.

10. D. Splitter, R. Hanson, and R.D. Reitz, "High Efficiency, Low Emissions RCCI Combustion by Use of a Fuel Additive", SAE 10FFL-0045, 2010.

11. J.M. Clarke and W.G. Berlinger, “A New Compression Ignition Engine Concept for High Power Density," Proceedings of the $18^{\text {th }}$ Annual Fall Technical Conference of the ASME Internal Combustion Engine Division, J. Caton, ed., vol. 27-1, book number G1011A, pp 45-52 (1996).

12. Animation of a compact compression ignition (CCI) engine, http://www.motivengines.com/page6/page6.html .

13. P. Van Blarigan, "Free-Piston Engine,” FY 2009 DOE Vehicle Technologies Program Annual Merit Review, Project ACE08, May 19, 2009. 
14. K. D. Edwards and R. M. Wagner, "Investigating Potential Efficiency Improvement for Light-Duty Transportation Applications Through Simulation of an Organic Rankine Cycle for Waste-Heat Recovery,” Proceedings of the ASME 2010 Internal Combustion Engine Division Fall Technical Conference, ICEF2010, San Antonio, September 12-15, 2010. 


\section{Appendix}

\section{List of colloquium participants}

Paul Najt (General Motors), Walt Weissman (Exxon-Mobil), Eric Curtis (Ford), Gary Hunter (AVL), Jerry Caton (Texas A\&M University), Noam Lior (University of Pennsylvania), Tony Greszler (Volvo), John Clarke (retired from Caterpillar), Ron Graves (Oak Ridge National Lab), Robert Wagner (Oak Ridge National Lab), Bengt Johansson (Lund University), Dan Flowers (Lawrence Livermore National Lab), Kellen Schefter (DOE), Terry Alger (Southwest Research Institute), Ron Reese (Chrysler), Don Stanton (Cummins), Gurpreet Singh (DOE), George Muntean (Pacific Northwest National Lab), Chris Edwards (Stanford University), James Yi (Ford), Dave Foster (University of Wisconsin), Steve Ciatti (Argonne National Lab), Harry Husted (Delphi), Stuart Daw (Oak Ridge National Lab), Pete Schihl (U.S. Army), Paul Miles (Sandia National Labs), Roy Primus (General Electric), John Kirwan (Delphi), and Tim Coatesworth (Chrysler).

\section{Meeting Agenda}

Wednesday, March $3^{\text {rd }}$

- 8:30 AM- Welcome/Introductions

o Summary of Objectives - Ron Graves

o Major Topics and Discussion Protocol- Stuart Daw

- 9:15-10:45 AM- Dave Foster, Chris Edwards, and Noam Lior - "Ideal thermodynamic efficiency limits for IC engines”; Open discussion.

- 10:45-11:00 AM- Break

- 11:00 AM-12:00 N- Ron Reese- "Efficiency penalty for current engines associated with drive transients/non-optimal operation”; Open discussion.

- 12:00 N-1:00 PM- Lunch and informal discussion.

- 1:00 PM-2:00 PM- Gary Hunter and Bengt Johansson- "Efficiency impacts of alternative fuels in current engines”; Open discussion.

- 2:00 PM-3:30 PM- Paul Miles, Terry Alger, Don Stanton- "Potential efficiency impacts of HECC or other advanced combustion modes"; Open discussion.

- 3:30-3:45 PM- Break

- 3:45-4:45 PM- John Clarke and Robert Wagner- "Potential efficiency benefits with changes in engine mechanical design and exhaust heat extraction.” and "Relative efficiency penalty in current engines related to friction and materials of construction”; Open discussion.

- 4:45-5:00 PM- Overview of next day plan and adjourn

- 6:30 PM- Offsite no host dinner and informal discusson. 
Thursday, March $4^{\text {th }}$

- 8:00-8:15 AM Breakout group assignments

- 8:15-10:15 AM Session 1 Breakout Groups

- 10:15-10:30 AM Coffee Break

- 10:30 AM-11:30 PM Session 2 Breakout Groups

- 11:30 AM -12:30 PM No Host Lunch and Informal Discussion

- 12:30-2:30 PM Breakout Group presentations and discussion

- 2:30 PM Adjourn 



\begin{tabular}{lll}
\hline & $\begin{array}{l}\text { First-law (\% of fuel } \\
\text { energy) }\end{array}$ & $\begin{array}{l}\text { Second-law (\% of } \\
\text { fuel availability) }\end{array}$ \\
\hline Work & 40.54 & 39.21 \\
Friction & 4.67 & 4.52 \\
Heat transfer to the & 17.23 & 13.98 \\
walls & & 1.16 \\
Aftercooler heat & 5.86 & .25 \\
transfer & & \\
Exhaust manifold & .39 & 12.73 \\
heat transfer & & \\
Exhaust gas to & 31.31 & $21.20(75.3)$ \\
ambient & & $0.81(2.9)$ \\
Irreversibilities & & $0.58(2.1)$ \\
Combustion & - & $1.66(5.9)$ \\
Thermal mixing & - & $0.57(2.0)$ \\
Intake throttling & - & $1.64(5.8)$ \\
Exhaust throttling & - & $1.69(6.0)$ \\
Fluid flow & - & \\
Compressor & - & \\
Turbine & - & \\
\hline
\end{tabular}

Figure 1. Summary of First and Second-Law balances for a sixcylinder, turbocharged and aftercooled, diesel engine operating at $224 \mathrm{~kW}$ and $2100 \mathrm{rpm}$. Presented by Noam Lior from the University of Pennsylvania. While First-Law analysis does not directly indicate combustion irreversibility, SecondLaw analysis reveals that combustion irreversibility loss in this case is over $21 \%$, which is in the typical range of $20-25 \%$ for current combustion engines. The other major efficiency losses are associated with heat loss to the combustion chamber walls and exhaust heat loss. For additional information see references [2] and [3].

(numbers in parentheses denote $\%$ of total irreversibilities). 
Restrained (SOFC)

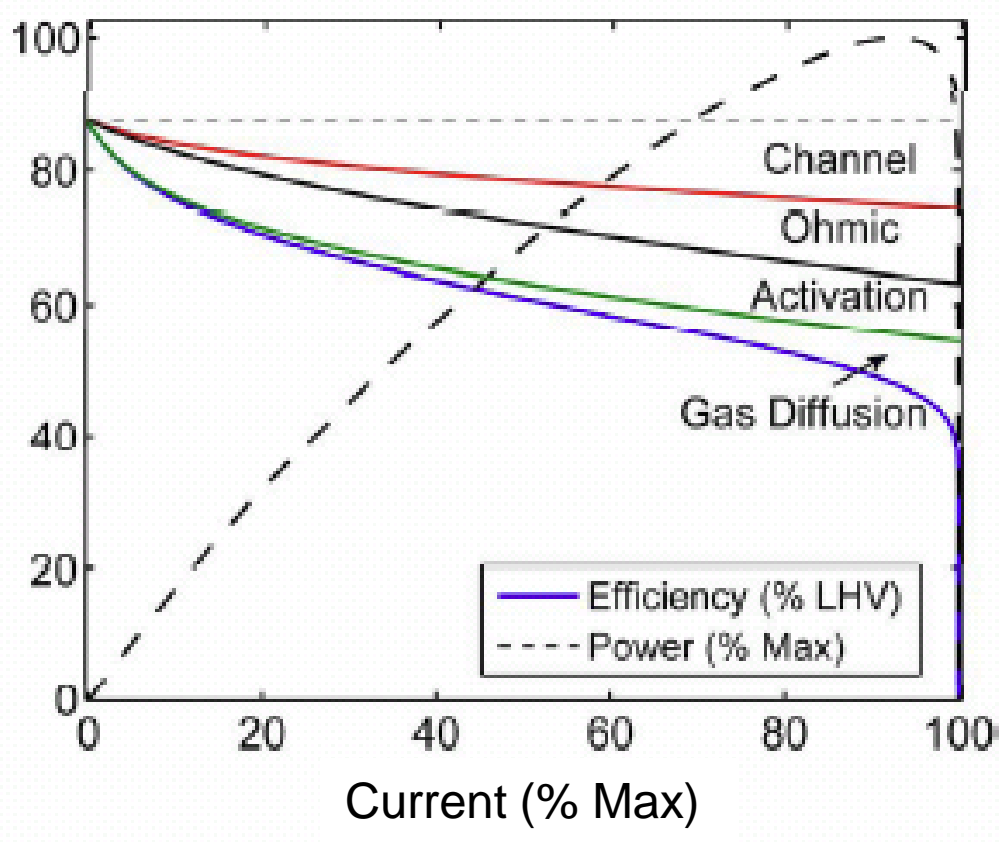

Unrestrained (DI Diesel $\left.{ }^{\star}\right)$

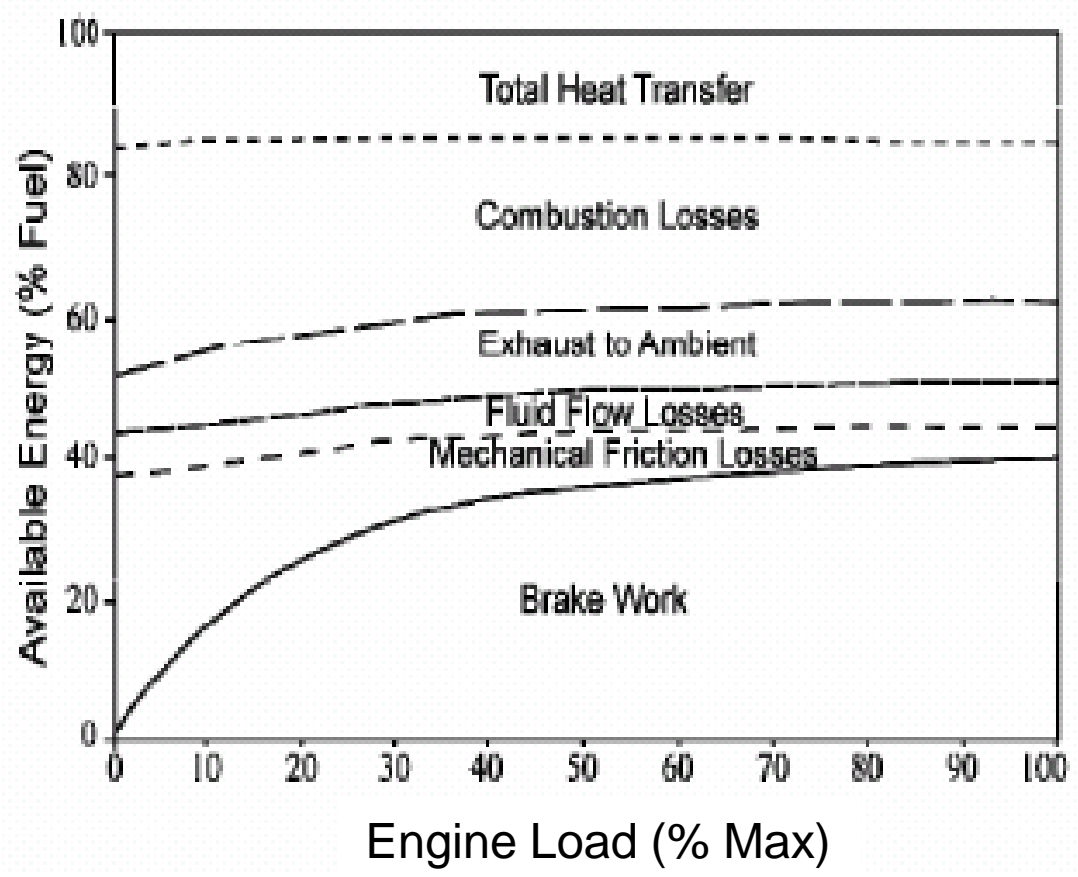

Figure 2. Comparison of the key efficiency differences between a conventional diesel engine and a solid oxide fuel cell (SOFC) as explained by Chris Edwards from Stanford University. Because of the constraining effect of the electrical load, the oxidation reactions in SOFCs operate closer to equilibrium than combustion engines, but electrical resistance, chemical kinetics and mass transport introduce new sources of irreversibility. One way to reduce the irreversibility of combustion engines is to increase compression ratio, but this involves a trade-off with increased friction. For the diesel engine, efficiency increases with load, while for SOFCs efficiency declines with load. See reference [4] for additional discussion. 


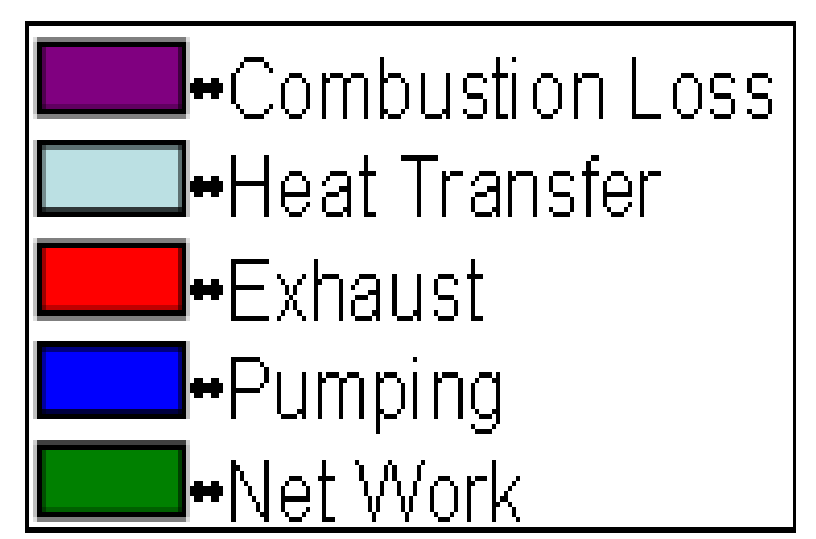

9-11 bar IMEP

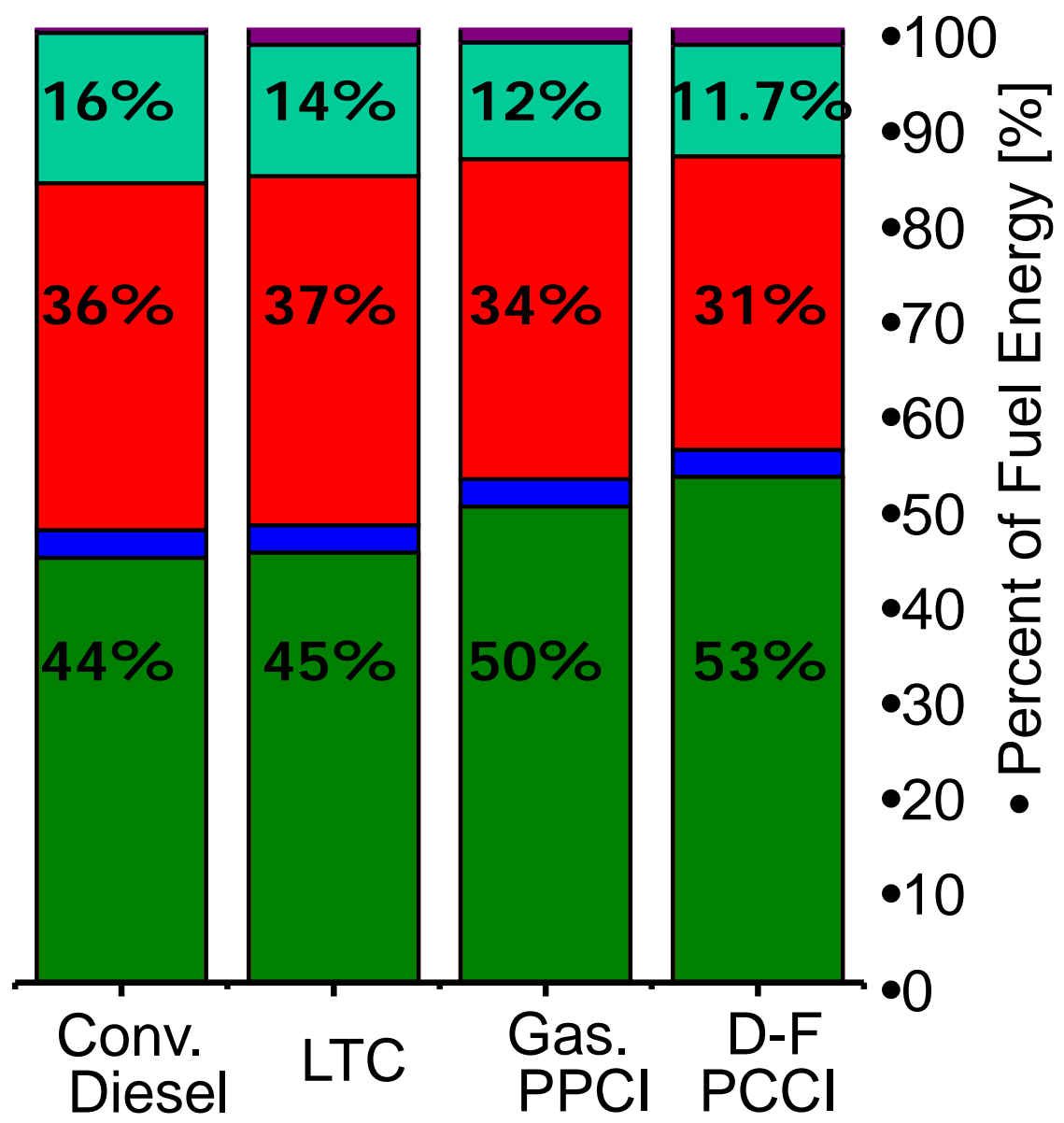

Figure 3. Summary of some recent achievements in peak indicated thermal efficiency in diesel engines with advanced low temperature combustion modes presented by Dave Foster from the University of Wisconsin. The leftmost bar is for conventional diesel combustion. The bars to the right depict observations for various forms of low temperature combustion, including partially premixed compression ignition (PPCl) and dual fuel PPCl. All efficiencies depicted are based on First-Law analysis. Loss terms indicated at the top of the bar graphs represent incomplete combustion of fuel. See references [5-8] for additional information. 


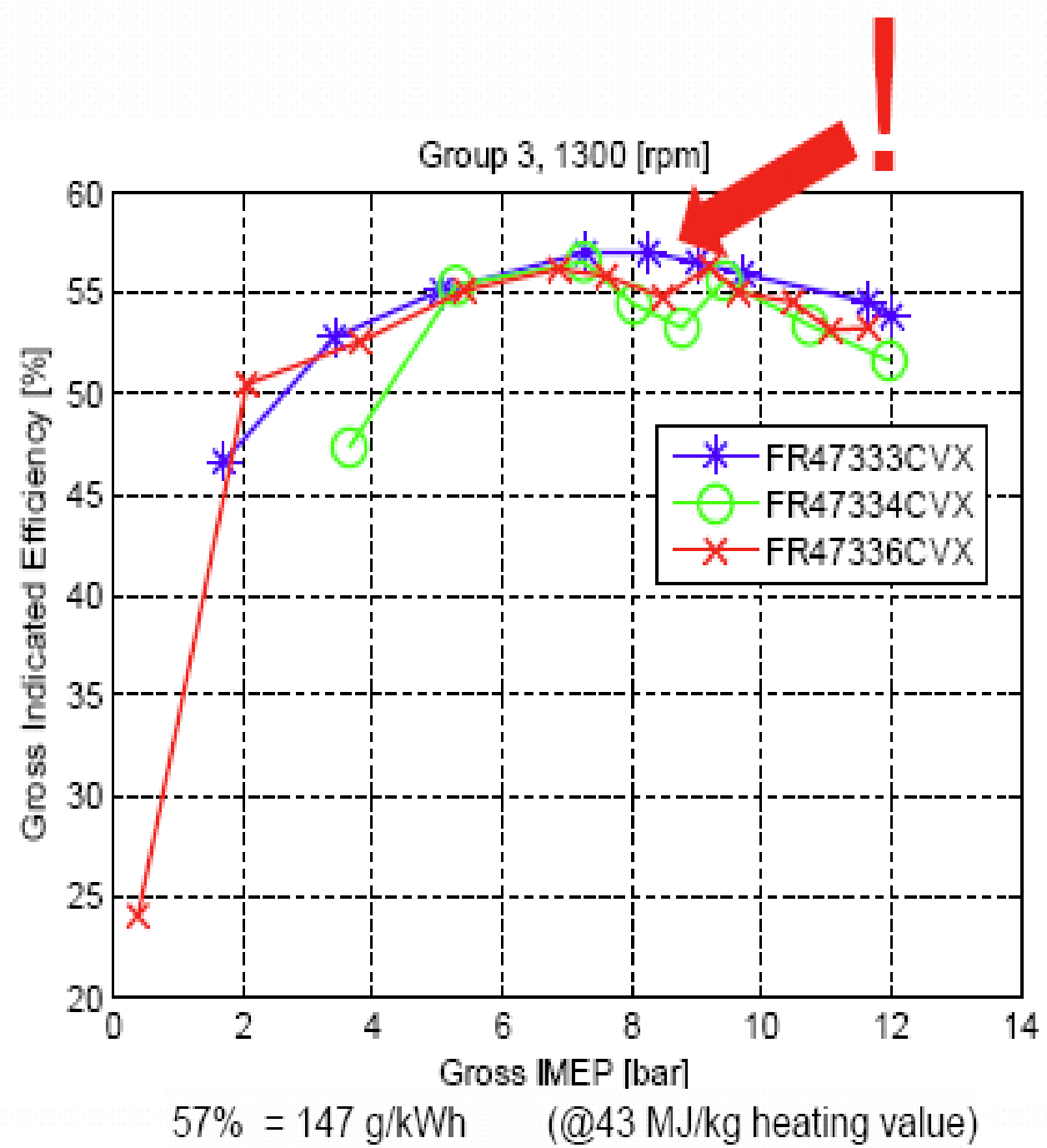

Figure 4. Recent experimental indicated peak efficiency results described by Bengt Johansson from Lund University. Indicated efficiencies of up to $57 \%$ were measured on a single-cylinder, 1.95-liter Scania engine with common rail injection operating in the partially premixed charge compression ignition (PPCl) mode. The three curves are for different gasoline blends ranging from 70 to 80 octane. The unburned fuel loss for this condition was just $0.1 \%$. Additional details are found in reference [9]. 


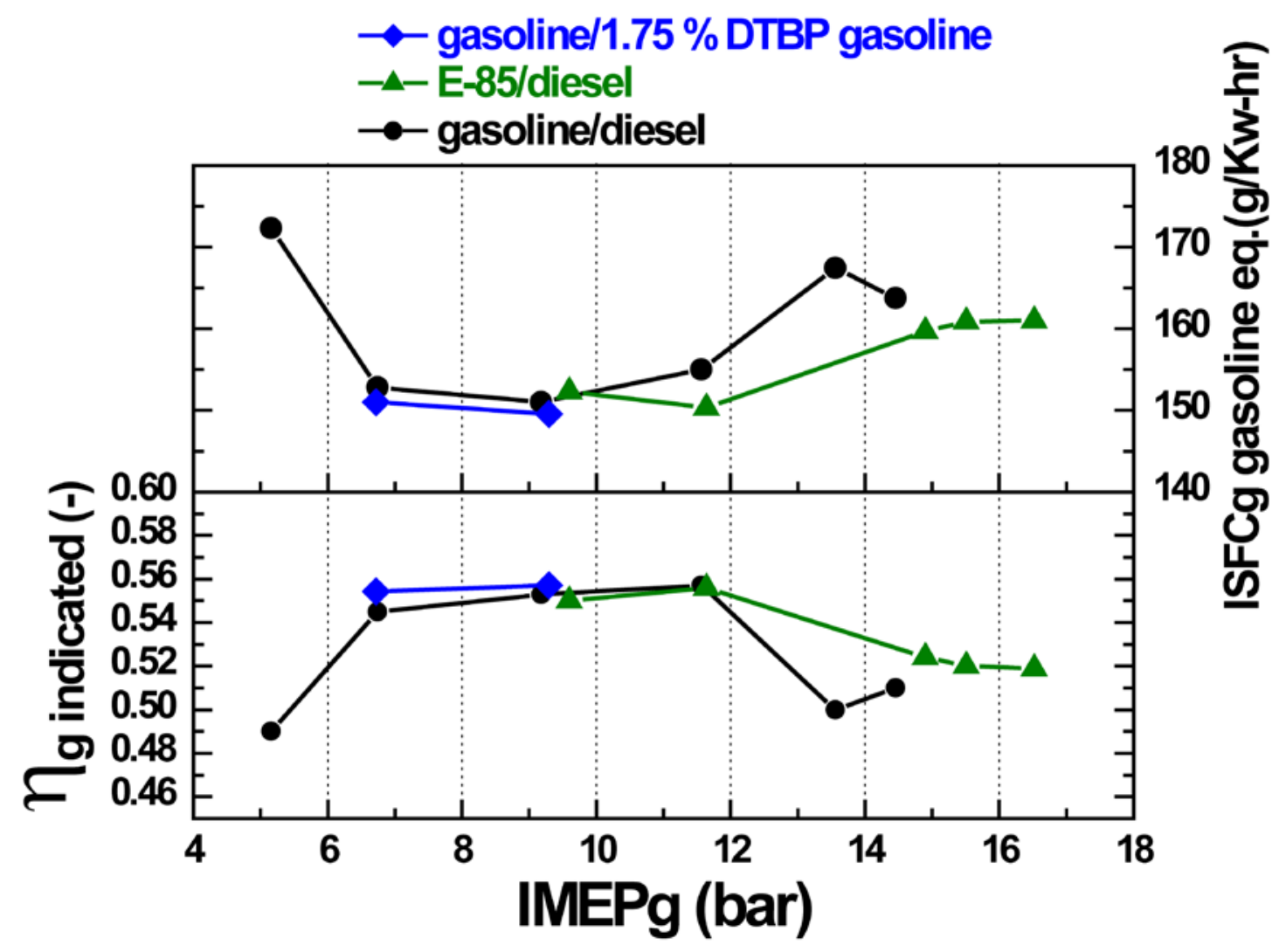

Figure 5. Additional examples of high efficiencies achieved in experiments at the University of Wisconsin on a type of low temperature dual-fuel combustion (referred to as reactivity controlled compression ignition, $\mathrm{RCCl}$ ) cited by Paul Miles from Sandia National Laboratories. These data were generated on a Caterpillar 3401 single-cylinder, 2.44-liter engine. Each curve represents the performance of a different duel-fuel combination: blue diamonds are for gasoline and gasoline containing di-tertiary butyl peroxide (DTBP); green triangles are for E85 and diesel; and black circles are for a gasoline and diesel combination. Peak indicated efficiencies exceeding $55 \%$ with low emissions have been reported. See reference [10] for additional details. 
$\mathrm{BSFC}, \mathrm{g} / \mathrm{kW} / \mathrm{h}$
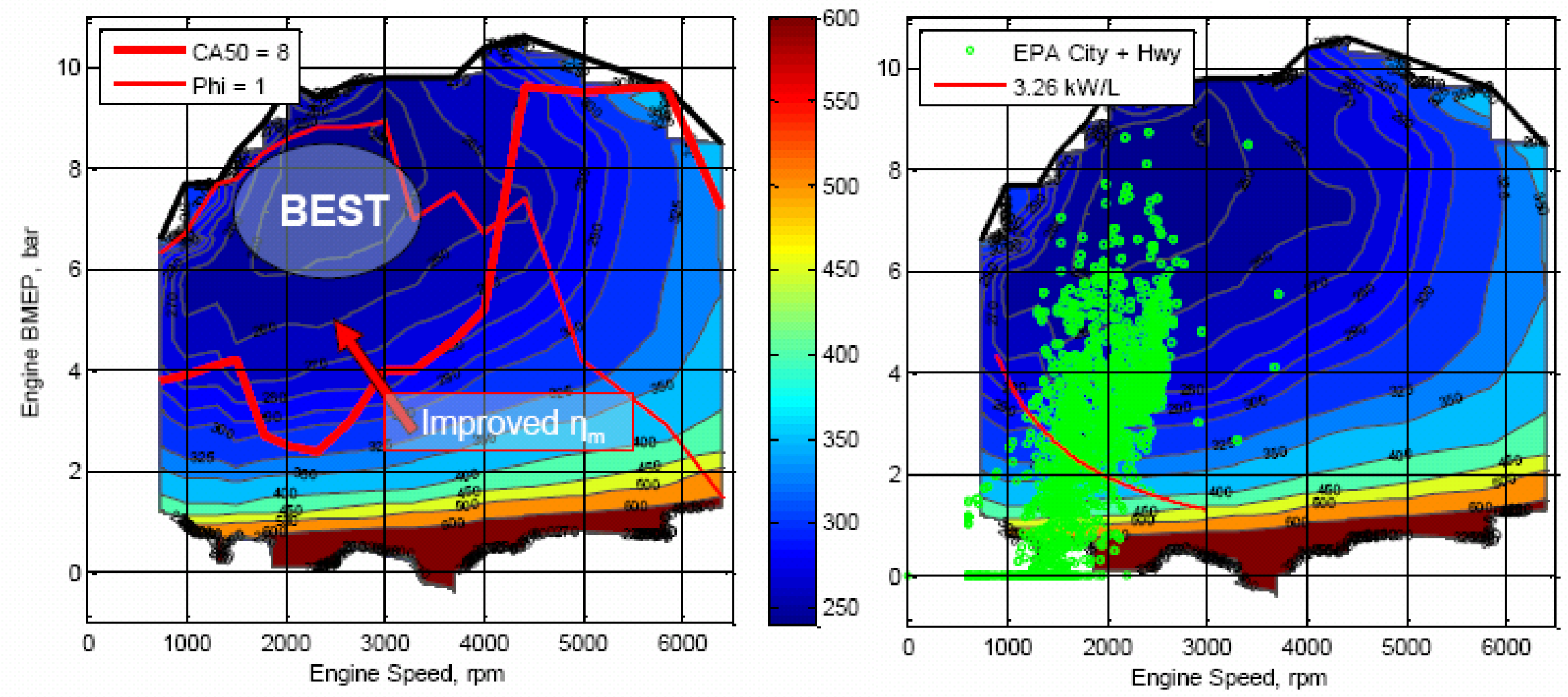

Figure 6. Representative brake specific fuel consumption (BSFC) map for a light duty vehicle discussed by Ron Reese of Chrysler. The left hand frame illustrates the engine speed and load combination (labeled 'BEST') where vehicle fuel consumption is minimized. The right hand frame illustrates where the engine actually spends most of its time during the EPA combined City and Highway driving cycles. Since the vehicle power demand is relatively low, the engine spends most of its time far from the point of peak efficiency. This mismatch between demand and peak efficiency is a strong function of the driving cycle details and engine control strategy. 
Conventional Diesel

combustion at high load

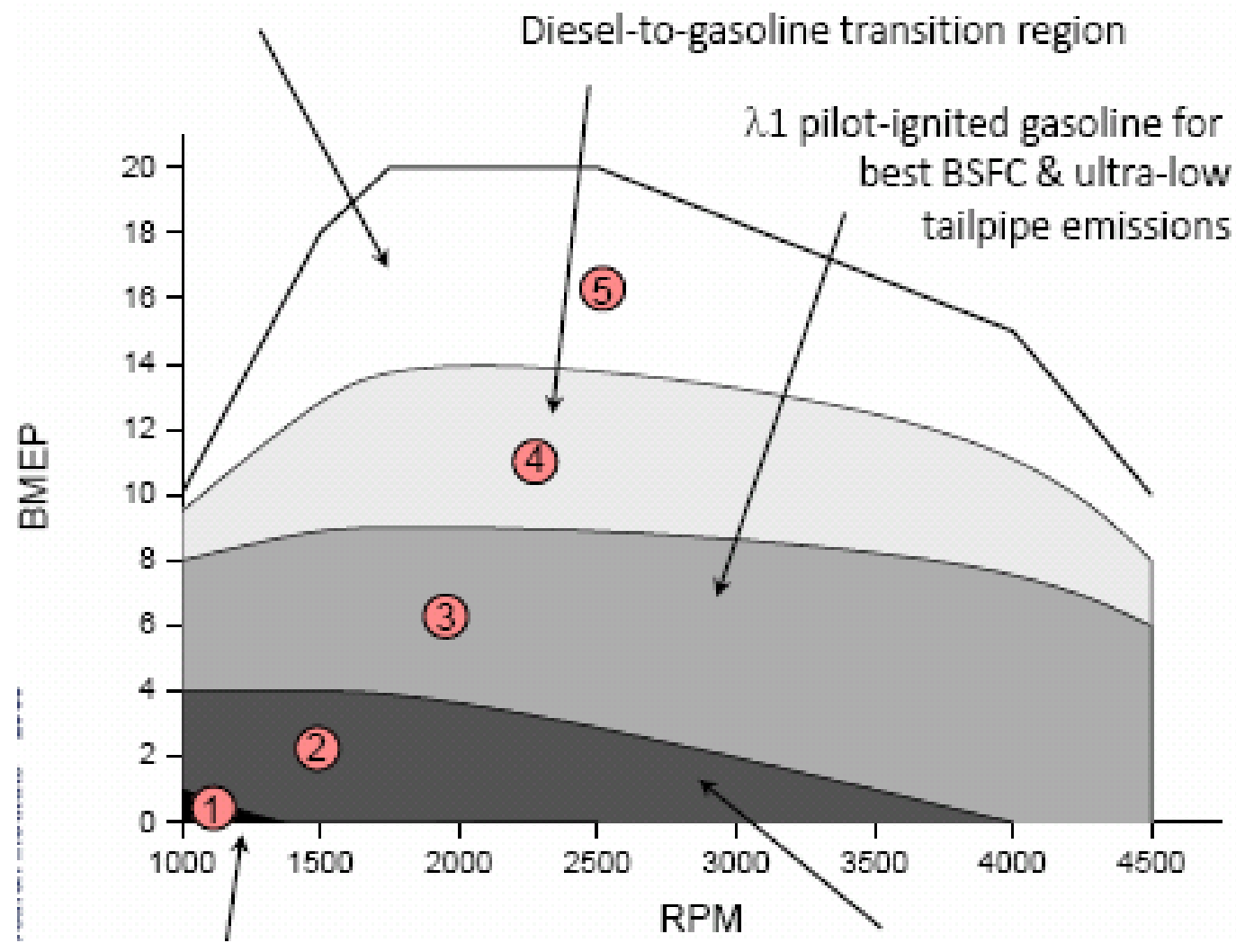

$\lambda 1$ SI gasoline for Bin 2 cold start and catalyst temperature maintenance
Figure 7. Operating map for a high efficiency dilute gasoline engine (HEDGE) utilizing dual-fueling and multi-mode combustion. Presented by Terry Alger of Southwest Research Institute. This plot is for a turbocharged EU5 diesel engine with spark ignition (SI) capability and gasoline port fuel injection. As speed and load change, the engine shifts between stoichiometric $(\lambda 1)$ and fuel-lean combustion using different proportions of gasoline and diesel fuels and different levels of exhaust gas recirculation (EGR). The operating states indicated by numbered circles are: 1) $S I \lambda 1$ gasoline with light EGR; 2) $S I \lambda 1$ gasoline with high EGR; 3) $\lambda 1$ gasoline with diesel pilot injection and high EGR; 4) lean diesel with gasoline support and moderate EGR; and 5) full diesel with light EGR. The SI $\lambda 1$ gasoline mode and three-way catalyst aftertreatment provide very low emissions during cold start. During lean operation lean NOx and particulate aftertreatment are required. 


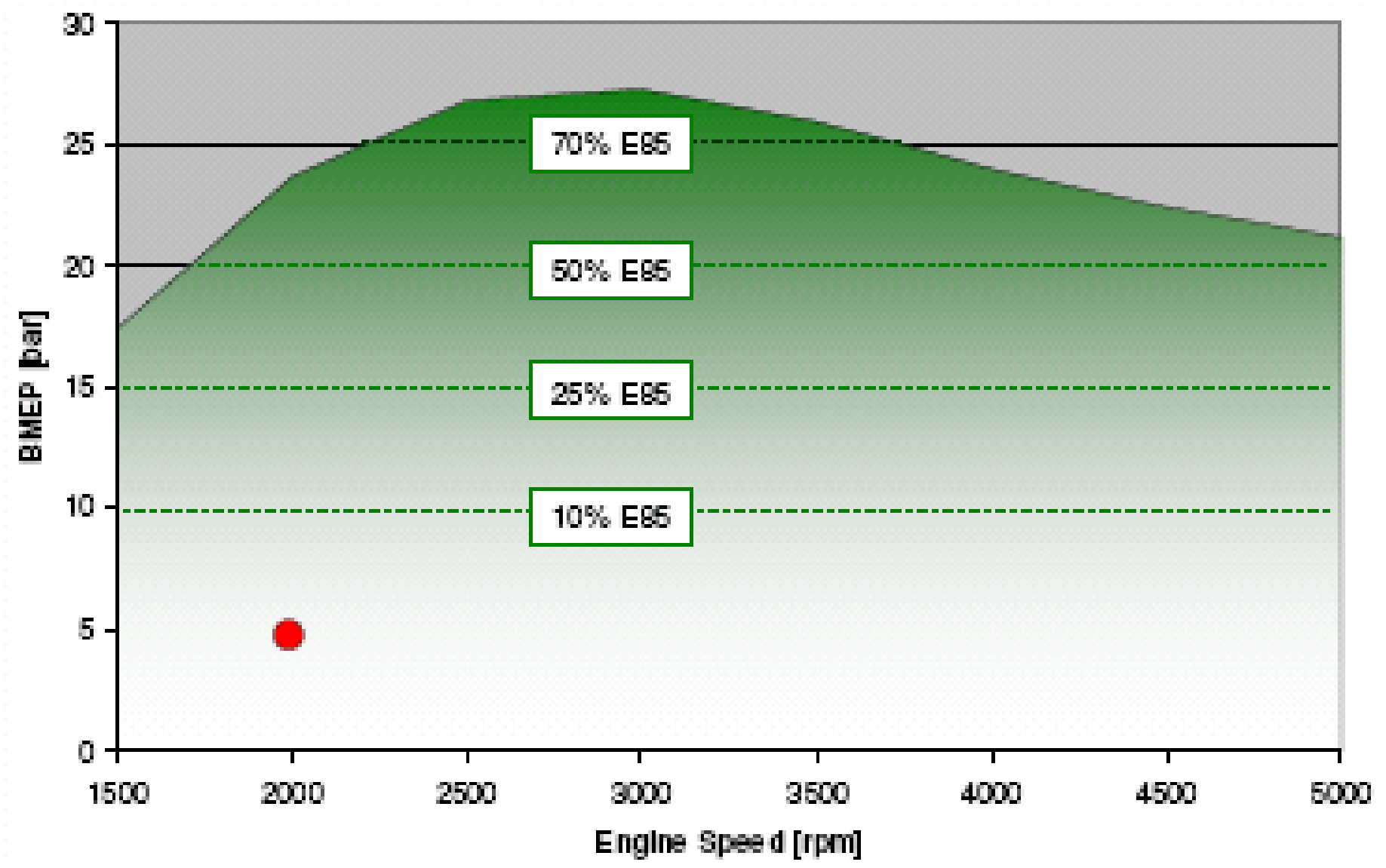

Figure 8. Operating map presented by Gary Hunter of AVL for a dual-fuel gasoline engine configured for supplemental E85 fueling. Gasoline is injected via port fuel injection (PFI), and E85 is injected as needed via direct injection (DI). When injected, E85 increases octane and enhances charge cooling (high heat of vaporization). This allows higher compression ratios without knock, increasing peak and cycle average fuel efficiency. The red circle (bottom left) is a typical driving condition for a downsized engine. At this condition the engine isn't knock limited (even with high compression) and only gasoline is fed. As BMEP increases to 10 bar, ignition timing has to be retarded to suppress knock, reducing efficiency. 10\% E85 addition suppresses the knock, allowing optimum ignition timing and higher efficiency. As BMEP increases further, E85 is increased still more to suppress knock as indicated by the dashed lines. 


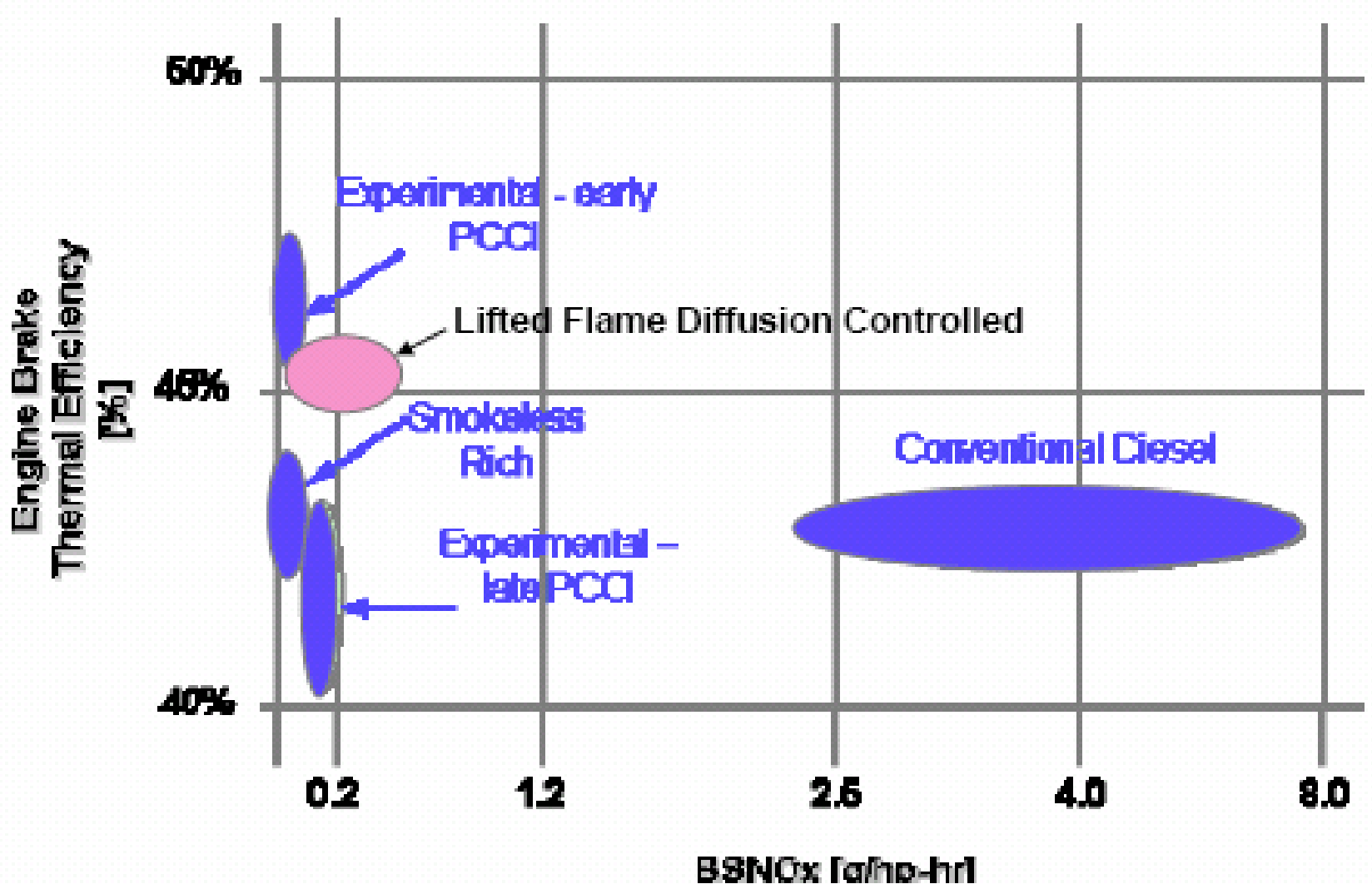

Figure 9. Efficiency and emissions impact of lifted flame diffusion combustion (LFDC) as described by Don Stanton of Cummins. In LFDC, liquid fuel penetration into the combustion chamber is reduced, while entrainment of combustion chamber gases and air into the fuel spray is enhanced. Lift-off length is broadened and the diffusion flame displaced from the cylinder wall, thereby reducing quenching, particulate and NOx formation, and wall heat loss. As indicated, brake thermal efficiency (BTE) and brake specific NOx(BSNOx) levels compare favorably with other types of advanced combustion. Key challenges include modifying intake valve closing conditions, modifying the fuel injection system, controlling the plume dynamics, downscaling to smaller bore engines, and development of transient controls. 


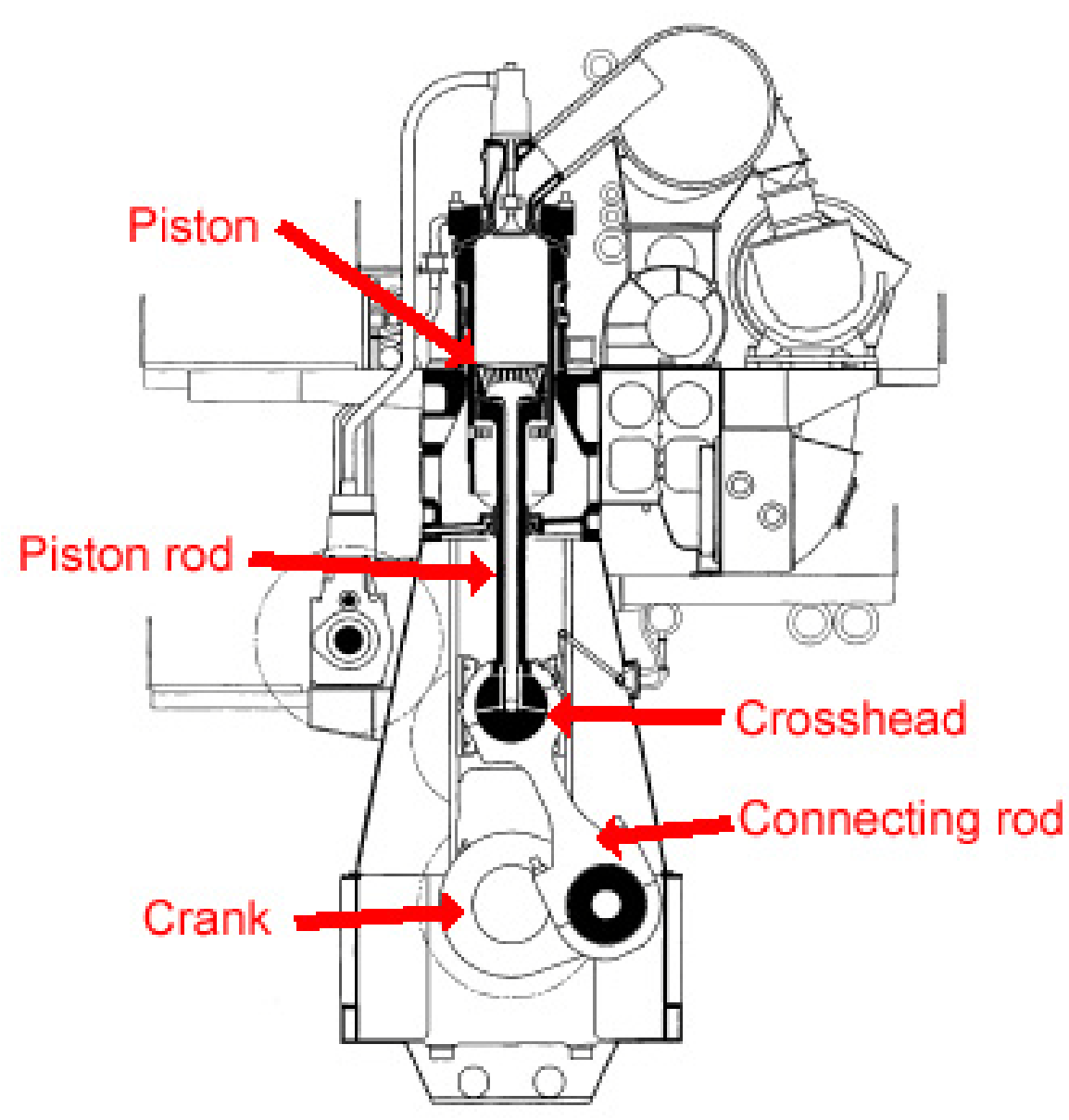

Figure 10. Illustration from John Clarke (Caterpillar, retired) depicting the major architectural features in marine diesel engines responsible for their high overall efficiency. A high stroke length to bore diameter ratio is favorable for combustion phasing. The low rotational speed produces less bearing friction. Typically, these engines also have large, efficient turbochargers and water-inter-cooling between the turbocharger and air intake. On ships it is possible to use direct drive with no transmission, thereby eliminating transmission friction. While these specific features would not be amenable for transportation applications, the underlying physics responsible for high efficiency might be exploited in alternative ways such as the compact compression ignition $(\mathrm{CCl})$ engine $[11,12]$. 


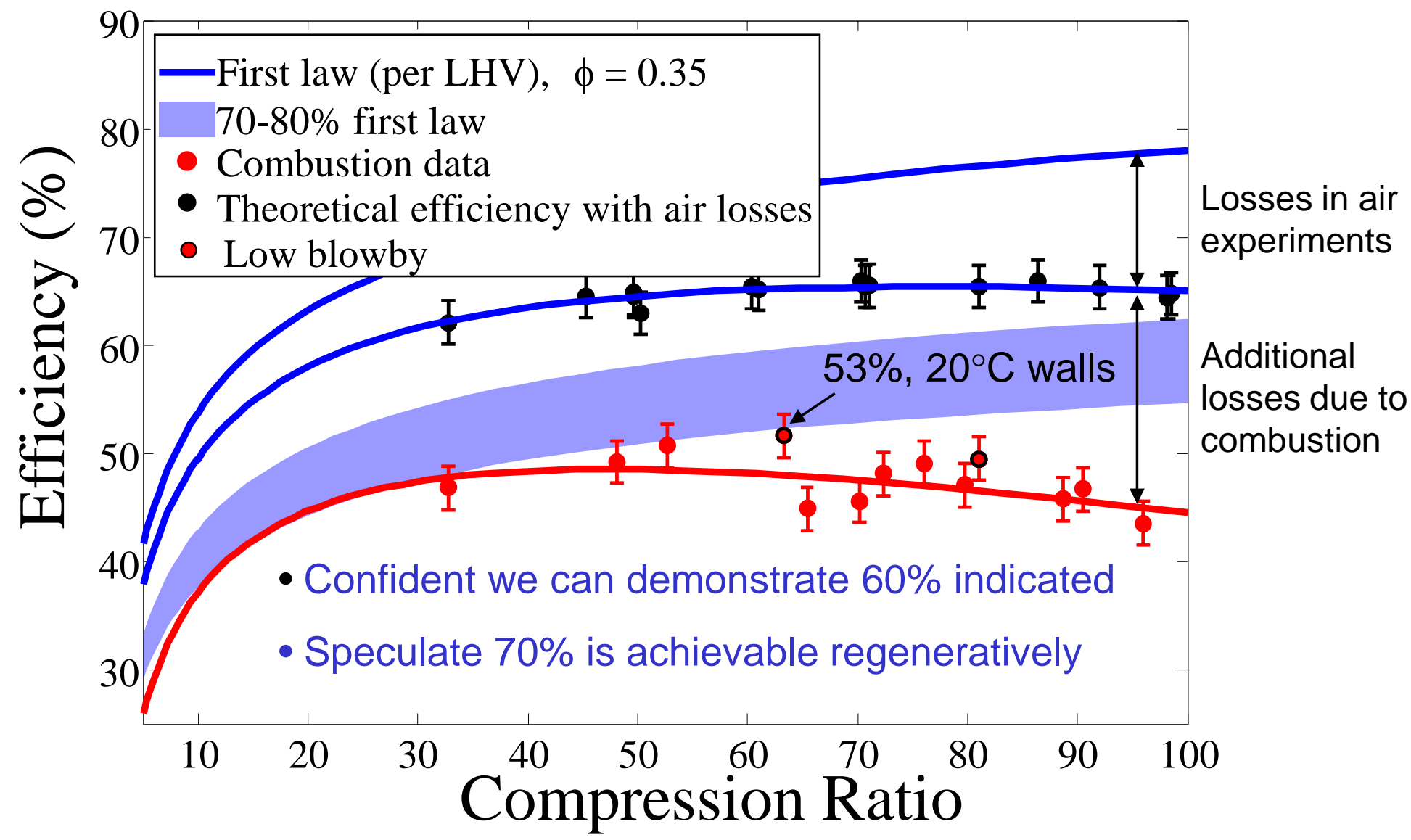

Figure 11. Indicated efficiencies observed for a single-shot, high-speed experimental free piston engine described Chris Edwards of Stanford University. Special non-rubbing wall seals allow compression ratios up to 100 without high friction. The top curve is for an Otto cycle with stoichiometric propane and air. The bottom curve (red) is experimentally measured. The middle curve is a corrected ideal curve after heat and mass transfer losses have been subtracted. The grey band is the fraction of theoretical performance expected for a well engineered system. Still higher indicated efficiencies are possible if regenerative heat recovery (e.g., with turbocharging, steam injection, or thermochemical recuperation) are included. 


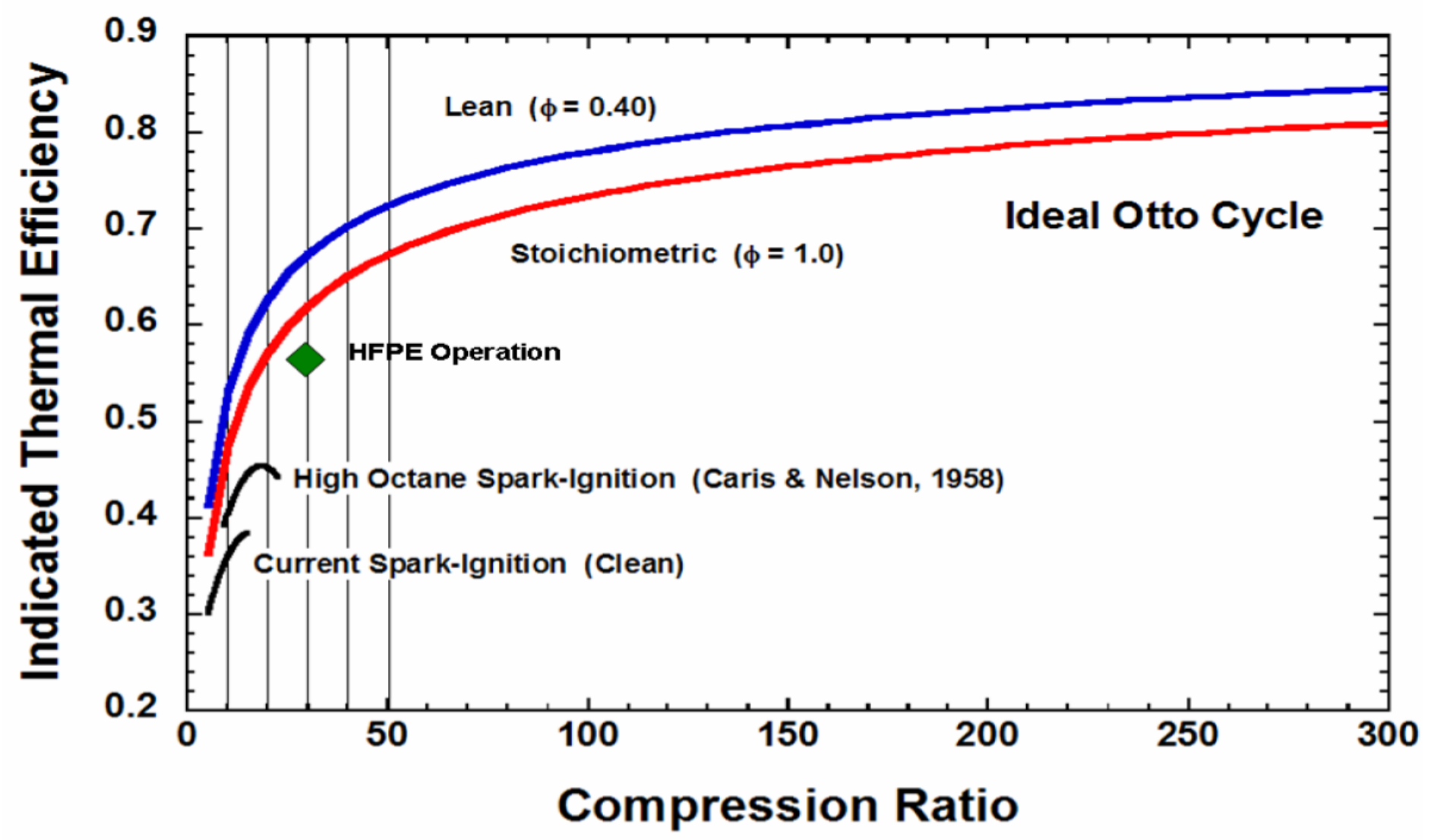

Figure 12. Summary of the theoretical potential for free piston engines cited by Paul Miles from Sandia National Laboratories. This plot was originally reported in reference [13]. The top (blue) curve illustrates the indicated efficiency of an ideal Otto cycle operating with a fuel-to-air equivalence ratio of 0.40 . For stoichiometric fueling the ideal indicated efficiency is reduced to the lower (red) curve. Recent experimental results for a hydraulic free piston engine (HFPE) are indicated by the green diamond. 


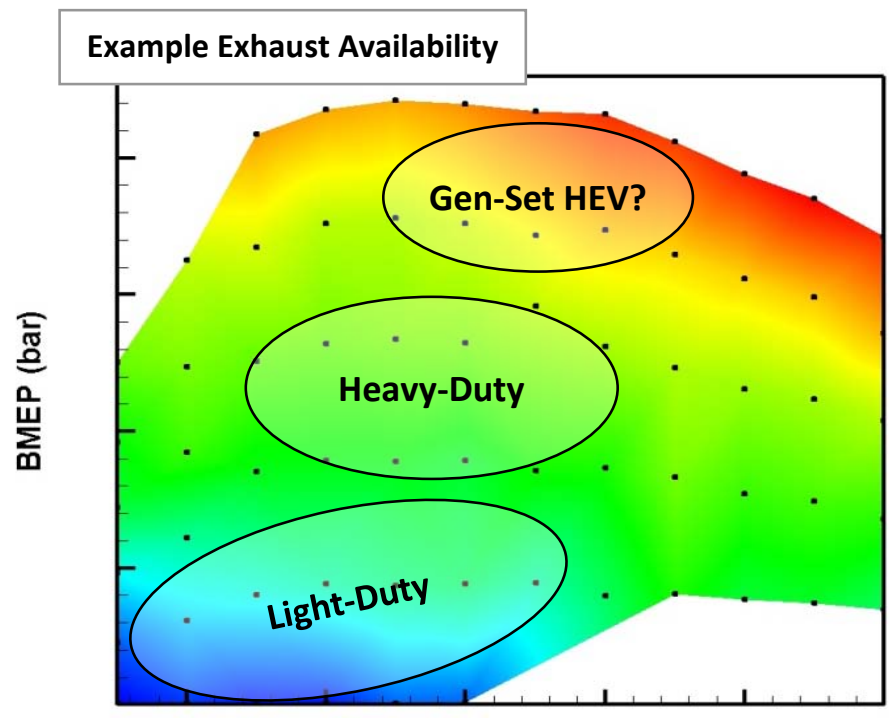

Engine Speed (rpm)

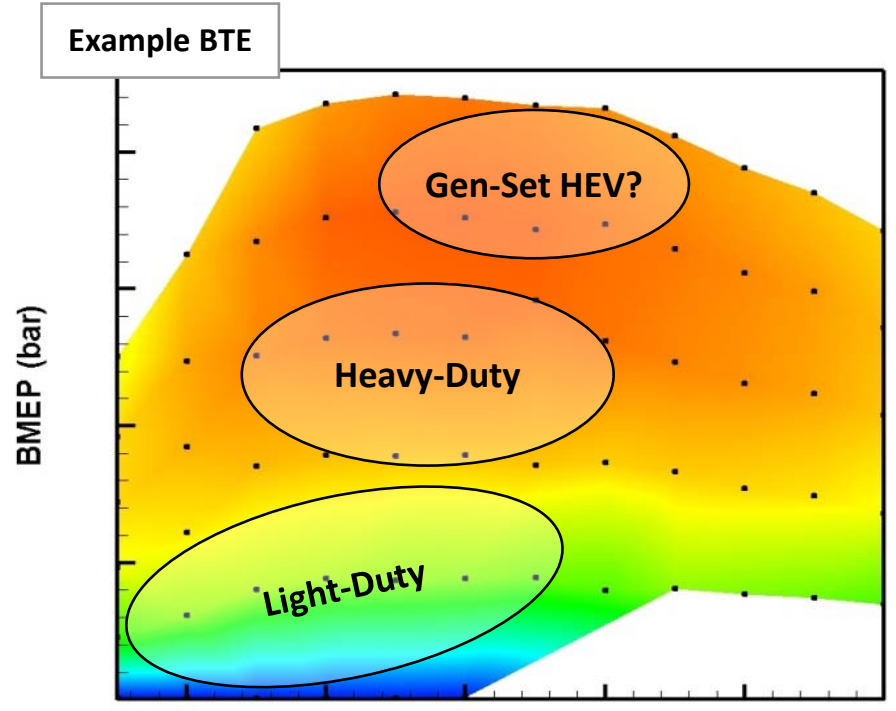

Engine Speed (rpm)
Figure 13. Exhaust heat recovery potential for a GM 1.9-liter diesel engine operating under light-duty (LD), heavy-duty (HD), and gen-set (GS) drive cycles. Presented by Robert Wagner of Oak Ridge National Laboratory. Redder colors indicate high availability and engine efficiency; bluer colors indicate lower availability and engine efficiency. LD cycles are not generally suited for exhaust heat recovery because of low exhaust temperature. Instead, turbocompounding may be more appropriate. HD cycles, which are less transient than LD cycles, have higher exhaust availability that could be utilized in bottoming cycles. If GS conditions were implemented in hybrid electric vehicles (with appropriate changes to hybrid controls), the constant high speed and load would yield both high engine efficiency and high exhaust availability. Additional details on these simulations can be found in reference [14]. 